\title{
CONTROL OF MODULAR CONVEYOR AND AUTOMATED HANDLING DEVICES INTERCONNECTION
}

\author{
Václav Cempírek', Jozef Gašparík², Vladislav Zitrický², Peter Blaho³ \\ 1 College of Logistics (Vysoká škola logistiky, o.p.s.), Palackého 1381/25, 75002 Přerov, Czech Republic, e-mail: \\ vaclav.cempirek@vslg.cz \\ 2 Department of Railway Transport, Faculty of Operation and Economics of Transport and Communications, \\ University of Zilina, Univerzitná 1, 010 26, Žilina, Slovakia, e-mail: jozef.gasparik@fpedas.uniza.sk, vladislav. \\ zitricky@fpedas.uniza.sk \\ 3 Railway of Slovak Republic, 1. mája 34, 010 01, Žilina, Slovakia, e-mail: blaho.peter@zsr.sk
}

Received: 2018.07.04

Accepted: 2018.08.06

Published: 2018.09.01

\begin{abstract}
The paper focuses on modular conveyors, mainly dedicated for the transport of parcel goods of various properties. Accent will also be put to their use in processes where the belt's resistance to higher temperatures or to mechanical damage is required. The solution is aimed on the use for installation in larger transport units, production as well assembly lines. The proposal of the conveyor design allows to handle different line sections (bends, broken sections, etc.) using a single drive. The conveyor track will be solved with aim to the transport of goods (products) by means of automated trolleys. A proposal for the synchronization of the conveyor track with an automated handling device will be presented, which will ensure the final phase of the production chain, the relocation of production to the warehouse of finished products. The authors will focus on the calculation of subsequent intervals for automated means of handling as well on determining the capacity of the conveyor track.
\end{abstract}

Keywords: modular conveyor, interconnection, parcel goods, capacity

\section{INTRODUCTION}

Transport and transportation of goods and materials are among the core activities in logistics. Recent studies show how the new technology of autonomous vehicles can change the form of logistics.

Although the recent very successful examples of variety use of autonomous mobile delivery vehicles such as Kiva Systems [1], today's manufacturing and logistics facilities are still largely dependent on manually operated vehicles [2]. Nowadays numerous commercial solutions using autonomous ground vehicles (AGVs) do exist, e.g., automated material handling vehicles by Komatsu's autonomous haul systems for the mining industry and Swisslog or Euroimpianti, significant improvements could be done in terms of their level of autonomy and deployment cost. In particular, the industrial state of the art for vehicle localization requires additional infrastructure, usually in the form of reflective markers or electromagnetic guides, for accurately determining vehicle pose [3]. This approach suffers from numerous disadvantages, as the markers have a high installation cost, requiring many man-hours of work by qualified personnel, they are sensitive to false positive readings and to changes in the environment which may obstruct the field of view of the vehicle, and they can get damaged or dirty in harsh industrial environments. Relevant current literature, such as $[4,5,6,7]$ unanimously identifies the ability of AGVs to selflocalize without additional infrastructure as one of the key technologies that will increase their performance and flexibility, thus enabling their widespread use.

An autonomous driving plays an increasingly important role in logistics. The autonomous ve- 
hicles in warehouses are able not only to transport the goods, but also to ensure their loading and unloading, which increases the efficiency of the whole process. Flexibility is increased by intelligent control linked to the ordering system.

The conveyor track is designed for the transport of goods (products) by means of automated vehicles. It is necessary to synchronize the conveyor track with an automated handling device, which ensures the final phase of the production chain, relocating the production to the warehouse of finished products.

The aim of the research is to propose the calculation of the capacity for the subsequent driving of automated means of handling and the determination of the capacity of the runway as a contribution to the forming of the industry 4.0.

From both a theoretical and practice perspective, the study's contribution is fourfold including: (i) a review of automated vehicles in the industry, (ii) an integrated theory of transportation in production systems defined by the utilisation of innovative AGV in operations, (iii) developed evaluation of capacity of transport capacity according to the mode of transport.

\section{FLEXIBLE CONCEPT OF MATERIAL FLOWS}

Modern manufacturing processes require increasingly flexible material flow concepts. Material flow must be in line with demand and must be environmentally friendly and healthy. In line with this trend, intelligent drive systems with autonomous control are increasingly used to supply material in production plants. They supply assigned places with low demands on time and space for the material needed. [8]

Autonomous (automatically) intelligent guiding vehicles (sets of vehicles) for continuous material flow then move independently on specified transport routes, for example, by magnetic point or magnetic tape navigation. Such a set automatically reaches the assigned individual locations for handling operations. A serviceman at the designated stand will ensure the unloading and loading of the material. In the automated material flow, both autonomous traction vehicles as well standard traction vehicles with E-frames and Cframes are used. [9, 10]

As the autonomous vehicle takes over driving and operating, the service staff can fully concentrate on work. This greatly improves the performance of handling operations and reduces the number of errors. The motion safety is provided by motion sensors that distinguish between the operator, other persons and obstacles. The autonomous vehicle can't either the obstacles drive round or, if the route is completely blocked, it stops. If a slower vehicle drives or congestion is in the front, the speed will be adapted to the immediate situation. As soon as the driving route is free, the autonomous vehicle will start again. It also recognizes the empty rack shelves and drive next. The crossroads are automatically overtaken after approval by the operator. The operator can decide whether to drive the vehicle manually or autonomously. The LED indicates whether the vehicle is operating in automated or manual mode, and that another optical signal indicates the direction of the autonomous vehicle.

\section{THE MATHEMATICAL EXPRESSION OF THE TRANSPORT AND MANIPULATION PROBLEM}

The mathematical expression of the transport and manipulation problem results from the fact that in m-various places, which can be denoted as sources $Z_{i}(i=1,2, \ldots, m)$, the material or handling agent is present in the amount of $\mathrm{M}_{z}$ $(\mathrm{i}=1, \ldots, \mathrm{m})$, which is required at the consumer site $S_{j}(j=1,2, \ldots, n)$ in the amount of $M_{s j}(j=1$, $2, \ldots, n)[11]$.

The cost of transporting the unit quantity of material from $\mathrm{Z}_{\mathrm{i}}$ to $\mathrm{S}_{\mathrm{j}}$ is $\mathrm{C}_{\mathrm{ij}}$. The transported quantity $\mathrm{M}_{\mathrm{ij}}$ must be determined so that the total transport costs are minimal. From this formulation, the mathematical expression of the task directly results, i.e. to find the minimum function:

$$
F_{(M)}=\sum_{i=1}^{m} \sum_{j=1}^{n} c_{i j} \cdot M_{i j}=\min
$$

The functions we look for are called special or critical functions. The following conditions apply to this function:

$$
\begin{gathered}
\sum_{i=1}^{m} M_{i j}=M_{1 j}+M_{2 j}+M_{3 j}+\ldots+M_{i j}+\ldots \\
+M_{m j}=M_{1 j} \quad(j=1,2, \ldots, m) \\
\sum_{j=1}^{n} M_{i j}=M_{i 1}+M_{i 2}+M_{i 3}+\ldots+M_{i j}+\ldots \\
+M_{i j}+\ldots+M_{n j}=M_{z i} \quad(i=1,2, \ldots, n)
\end{gathered}
$$

which express the need to meet, respectively. occurrence and

$$
M_{i j} \geq 0(i=1,2, \ldots, m ; j=1,2, \ldots, n)
$$


which provides transportation in one direction.

Where applicable:

$$
\sum_{i=1}^{m} M_{z i}=\sum_{j=1}^{n} M_{s j}
$$

we are talking about a balanced (closed) transport, respectively handling process.

In case that:

$$
\begin{gathered}
\sum_{i=1}^{m} M_{z i}>\sum_{j=1}^{n} M_{z i} \quad \text { or } \\
\sum_{i=1}^{m} M_{z i}<\sum_{j=1}^{n} M_{s j}
\end{gathered}
$$

It is unbalanced (open) traffic, respectively unbalanced (open) handling process.

Handling processes increasingly affect the stability and efficiency of the production process. Their objective necessity and their contribution to value creation is at odds with their underdevelopment.

\section{THEORY OF THE TRANSPORT SYSTEM IN PRODUCTION}

Transport in the production sphere meets the needs of the production technology, the division of activities, and especially the cooperation and specialization of production between the different phases and the production phases, up to the final product. $[11,12,13]$

This transport can be characterized mainly by the following features:

- the transport product is the intangible useful effect of relocation (shipment), it is not storable, and therefore any imbalances in the transport requirements need to be covered by the reserves of both fixed and mobile means and live labour,

- the transport process is continuous and continuous (according to the organization of production) in time, the completion of one transport does not end the whole process but immediately follows up on the next relocation,

- the transport process is uneven in time and depends not only on the uneven production and sales, but also on the imbalance of subcontracts from suppliers,

- the transport process is batch, that is, the actual relocation takes place in batches, the size of which is given by the limited capacity of the transport unit,

- movement of the transport unit along the transport route, i.e. the dynamics of the pro- cess, which can be expressed only by vector quantity, direction, distance and time.

The subject of the research theory of such a transport system is:

- Exploring the actual mode of relocation, i.e. the technological reality of the transport process. From this point of view the effects can be explored in networking and optimal hierarchies of transport networks with regard to needs; determining the permeability of transport networks and their segments and optimal location of contact between two or more homogeneous transport networks to create a heterogeneous network;

- Explore the technical means through which the relocation process takes place. At this level the effects can be explored in the tasks of interacting the movement of transport means along the transport route; the construction of the transport route and the means of transport and the optimization of the construction of the means of transport and of the transport routes from the point of view of transport traffic costs;

- And exploring the effects of relocation.

Effects in this level can be explored in the tasks of optimal traffic load; determining the optimal flow in transport networks and optimal distribution of traffic streams in these networks or optimal node location in the tasks of technological reality.

\section{BELT CONVEYORS}

Belt conveyors belong to a group of conveyors with a flexible pulling element 14 . The closed traction element circulates around the end drums and performs the carrying function of the conveyed material, and overcomes all the resistances that arise in the upper and lower return branches of the belt $[12,14,15]$.

The main advantages of belt conveyors can be summarized as follows:

- continuous high hourly performance,

- suitability for the transport of all types of bulk materials,

- long and very long distances with a pitch angle of $18^{\circ}$,

- low friction and wear, noiseless operation and safe and reliable operation,

- simple construction of conveyor equipment with easy assembly and disassembly. 
One of the disadvantages is the large number of lubrication points and heavy belt maintenance when transporting materials that damage the conveyor belt, such as abrasive and coarse grain materials. For our consideration, the belt conveyor will be used to transport piece goods in conjunction with autonomously controlled vehicle set, see Figure 1. The application of the conveyor belt and the autonomously handling vehicle is applied, for example, in the production of sanitary technology. At the transfer point, at the end of the belt conveyor, the products are loaded into an autonomously controlled carrier with a rack structure, and after filling all the positions, they leave to the baking furnace and then to the dispatch warehouse.

Conveyor capacity calculation is routed to determine the capacity of adjacent autonomously guided vehicle sets.

The capacity calculation is based on the determination of the basic parameters of the conveyor that determine its capacity. Based on the given quantities, we determine from the relationship the quantity transported:

$$
Q=3600 . A \cdot v \cdot \rho
$$

where: $Q-$ conveyor capacity $\left[\mathrm{t} \cdot \mathrm{h}^{-1}\right]$

$A$ - cross-section $\left[\mathrm{m}^{2}\right]$

$V$ - speed $\left[\mathrm{m} \cdot \mathrm{s}^{-1}\right]$

$r$ - density $\left[\mathrm{kg} \cdot \mathrm{m}^{-3}\right]$
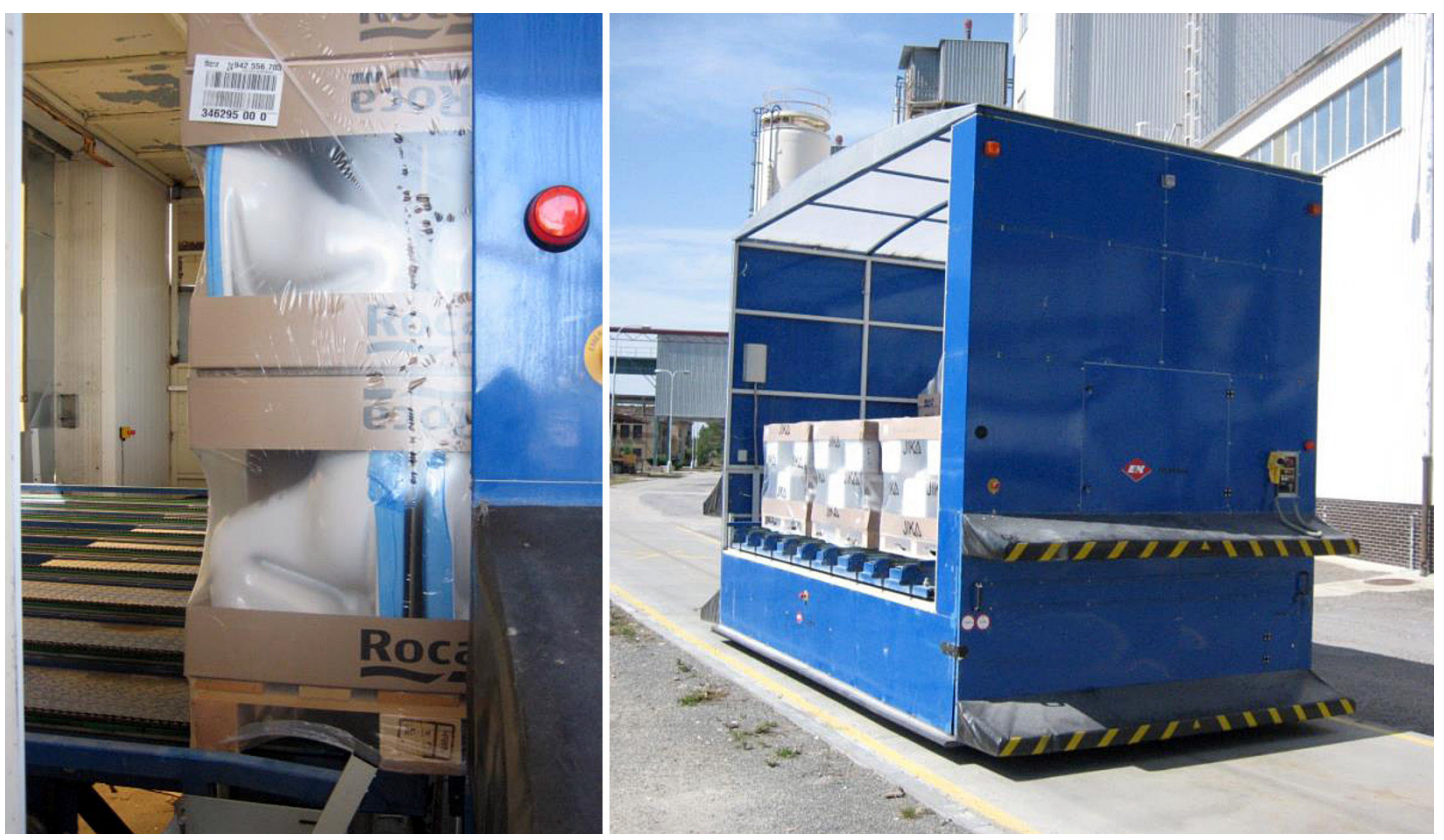

Fig. 1. Example of the continuity of the pallet conveyors to the autonomous trolley in the production process

\section{PARAMETERS OF AUTOMATICALLY CONTROLLED VEHICLES}

The organization of the transport of autonomously driven vehicle sets can be controlled on base of capacity assessment knowledge in other technological practicies $[15,16,17,18,19,20]$ using the following indicators:

- Capacity of the device,

- Degree of occupation,

- Capacity utilization factor,

- Speed of autonomously driven vehicle sets

The capacity of the device $\mathrm{n}$ is defined as the performance expressed in the number of traction vehicle sets that can be driven on the equipment without reducing the required quality of the transport process.

The capacity is the largest range of controlled vehicle sets, determined with regard to the time required to perform prescribed inspections, maintenance of the operating equipment, and also with regard to the need to compensate irregularities and disturbances. Capacity calculation can be made according to this formula:

$$
n_{\text {prakt }}=\frac{T-\left(T_{\text {vyl }}+T_{\text {stal }}\right)}{t_{\text {obs }}+t_{\text {dod }}+t_{\text {rus }}}
$$

where: $T$ is the time period for which the capacity [min] is calculated,

$T_{v y l}$ is the total is the total time during which the operation equipment is exclud- 
ed from service during the time period for prescribed inspections, repairs and maintenance [min]

$T_{\text {stal }}$ is the total length of permanent manipulations, i.e. the time at which the operating facility or element is occupied during period $\mathrm{T}$ by other operations than those in which the capacity is determined [min] $t_{o b s}$ is the technological time of occupation of a given operating device or element by one towing device in which the capacity [min] is calculated,

$t_{d o d}$ is the average time attributable to one towing device that needs to be extended to occupy the element because its release prevents the occupation of another element, $t_{\text {rus }}$ is the average time of probable interference of drives occurring in places of potential threat due to the impossibility of simultaneous drives on the given element [min].

The degree of occupancy $\mathrm{s}_{\mathrm{O}}$ represents the occupancy rate of the investigated device, which is calculated as the ratio of the total occupancy time of the investigated $\mathrm{T}_{\mathrm{obs}}$ device (the operating section, the depot handling run, etc.) to the total calculation time $\mathrm{T}$, minus the operation breaks (eg repairs, maintenance) and permanent manipulations $\mathrm{T}_{\text {stal }}$ (activities that occupy the investigated facility, but are not counted as occupation).

$$
S_{o}=\frac{T_{o b s}}{T-\left(T_{v y l}+T_{\text {stal }}\right)} \quad[-]
$$

The utilisation of the capacity of the investigated device expresses the percentage utilization factor $K_{p r a k t}$, which is determined by the ratio between the numbers of regular autonomous vehicle, sets $N_{\text {reg }}$ to practical capacity $n$.

$$
K_{\text {prakt }}=\frac{N_{\text {reg }}}{n} \cdot 100[\%]
$$

Other parameters that are important for setting the operating order include:

The basic speed is determined with respect to the set periodic time of the production line. Speed should not jeopardize the safety of work in the given segments, which are driven by autonomously vehicle sets. Vehicles react to touch any object that interferes with the driving profile, stopping immediately.

Driving time is the time period that autonomously guided vehicle require to move a certain distance between two workplaces or between a supermarket and a first service place. The driv- ing time starts from the moment the set is moved from the place (depo, workplace) and ends with stopping the set in the depot or the serviced workplace it regularly serves.

Operation intervals (for depots) determine the collision point, which is the head (the point of the contact of guiding autonomous vehicles). Depending on the direction of travel, the first and second vehicle sets are divided into service intervals of vehicle sets of the same direction and vehicle sets of the opposite direction.

The technological time of occupation $t_{\text {obs }}$ is determined for collision point, which is the section between the workstations. It is possible to entitle such an interval as a headway interval (M). It is the interval between two vehicle sets, also the time needed for driving on the distance between the first and second vehicles.

\section{CONCLUSION}

Handling processes significantly affect the stability and efficiency of the manufacturing process. When assessing the capacity of logistics equipment in production, it is necessary to apply different approaches depending on the operating equipment. Belt conveyors have the capacity defined by the conveyor basic parameters, which are in particular cross-section, density and speed. The resulting capacity of modern autonomously guided vehicles can be determined in deterministic conditions as the capacity of a continuous sequence of several technical devices can be referred to as the capacity of the operating equipment that we determine based on the capacity of the least efficient equipment. Additional qualitative indicators such as degree of occupation, capacity utilization factor, and speed of autonomously driven vehicle sets have been proposed.

Capacity solutions can also use simulation tools that enable the logistics facility to evaluate the capacity of the logistics facility based on the real-time model. The simulation modelling simulation modelling capability provides a comprehensive assessment of the device's capacities, although the result is only suboptimal in terms of the general approach depending on the simulation process. The range of input data required by the simulation model (detailed description of the infrastructure and the dynamic properties of vehicles) as well as the time consuming of the simulation assessment is problematic. On the 
other hand, the new possibilities that simulation modelling brings are prerequisites for its successful implementation in those cases where it is well founded.

\section{Acknowledgements}

The paper is supported by the VEGA Agency by the Project 1/0791/18 "The Assessment of Economic and Technological Aspects in the Provision of Competitive Public Transport Services in integrated Transport Systems", that is solved at Faculty of Operations and Economics of Transport and Communication, University of Žilina.

\section{REFERENCES}

1. Wurman P.R., D'Andrea R. and Mountz, M.. Coordinating hundreds of cooperative, autonomous vehicles in warehouses, AI magazine 1 (29), 2008, 1-19.

2. Sabattini L., Digani V., Secchi C., Cotena G., Ronzoni D., Foppoli M. and Oleari F. Technological roadmap to boost the introduction of AGVs in industrial applications, In IEEE International Conference on Intelligent Computer Communication and Processing (ICCP), Cluj-Napoca, Romania 2013, 203-208.

3. Vasiljević G., Miklić D., Draganjac I., Kovačić Z. and Lista P. High-accuracy vehicle localization for autonomous warehousing. Journal of Robotics and Computer-Integrated Manufacturing. C (42), 2016, 1-16.

4. Zheng K., Tang D., Gu W. and Dai M. Distributed control of multi-AGV system based on regional control model. Production Engineering; 7 (4), 433-441.

5. Möhring R.H., Köhler E., Gawrilow E. and Stenzel B. Conflict-free Real-time AGV Routing. Operations Research Proceedings. Vol. 2004, Springer, Berlin, Heidelberg 2005, 18-24.

6. Ullrich G. Automated Guided Vehicle Systems. Springer, 2015.

7. González D., Romero L., Espinosa M. D. and Domínguez M. An optimization design proposal of automated guided vehicles for mixed type transportation in hospital environments. PLoS ONE 12 (5), 2017

8. Buchholz, J. Clausen, U. and Vastag, A. Handbuch der Verkehrslogistik. Springer 1998.
9. Scholz-Reiter B., Windt K. and Freitag M. Autonomous Logistic Processes - New Demands and First Approaches. Monostori, L. Proc of 37th CIRP International Seminar on Manufacturing Systems. Hungarian Academy of Science, Budapest, Hungary, 2004, 357-362.

10. Scholz-Reiter B., Kolditz J. and Hildebrandt T. Engineering autonomously controlled logistic systems. International Journal of Production Research, 47 (6), 1449-1468

11. Pastor O. and Tuzar A. Theory of Transport Systems. Aspi Wotlters Kluwer, 2007.

12. Jasaň, V. et al. Theory of transport and handling equipment. Alfa, 1989.

13. Kuptcova A., Prusa P., Fedorko G. and Molnar V. Data mining workspace as an optimization prediction technique for solving transport problems. Transport Problems 11, 2016, 21-31.

14. Molnár V., Fedorko G., Andrejiová M., Grinčová A. and Michalik P. Online monitoring of a pipe conveyor. Part I: Measurement and analysis of selected operational parameters. Measurement 94, 2016, 364-371.

15. Bode W. and Rüdiger W. Preuss: Intralogistik in der Praxis. Wirtschafts Verlag W. V. GmbH, 2004.

16. Fedorko G., Husakova N. and Dudas G. Design of allocation of new technological equipment within the frame of production process in company Getrag Ford Transmissions Slovakia, s.r.o. Acta Montanistica Slovaca 15, 2010, 14-22.

17. Kampf R., Stopka O., Bartuška L. and Zeman K. Circulation of vehicles asan important parameter of public transport efficiency. Proc. of the 19th International Scientific Conference on Transport Means, Kaunas University of Technology, 2015, 143-146.

18. Kendra M., Babin M. and Barta D. Changes of the infrastructure and operation parameters of a railway line and their impact to the track capacity and the volume of transported goods. Procedia - social and behavioural sciences, 48, 2012, 743-752.

19. Žul'ová L., Grega R., Krajňák J., Fedorko G. and Molnár V. Optimization of noisiness of mechanical system by using a pneumatic tuner during a failure of piston machine. Engineering Failure Analysis 79, 2017, 845-851.

20. Lonkwic P., Różyło P. and Dębski H. Numerical and experimental analysis of the progressive gear body with the use of finite-element method. Eksploatacja i Niezawodnosc - Maintenance and Reliability 17, 2015, 544-550. 